Correspondence:

Jan Van Bavel

Department of Sociology, KU Leuven

Van Evenstraat 2B

B-3000 LEUVEN

Belgium

Does an effect of marriage duration on pre-transition fertility signal paritydependent control? An empirical test in 19th century Leuven, Belgium

Short title: The effect of marriage duration on fertility

dr. Jan Van Bavel, Department of Sociology, Faculty of Social Sciences, Catholic University of Leuven

September 2002 


\title{
Does an effect of marriage duration on pre-transition fertility signal parity- dependent control? An empirical test in 19th century Leuven, Belgium
}

dr. Jan Van Bavel, Department of Sociology, Faculty of Social Sciences, Catholic University of Leuven

\begin{abstract}
$\underline{\text { Abstract }}$
It has been demonstrated for many pre-industrial populations that the age at marriage, or marriage duration, influences age-specific marital fertility but it remains unclear why. Several mechanisms may be responsible for it. Often cited are secondary sterility or increased subfecundity associated with parity, declining coital frequency, the age difference between the spouses, and, importantly, parity-dependent fertility control. If the latter mechanism would be partly responsible for the marriage duration effect in pre-transition populations, it would contradict the concept of the modern fertility transition as the (r)evolution from parityindependent to parity-dependent fertility. This article investigates the importance of the alternative explanations cited. By applying a multivariate Poisson regression approach to the fertility data from two birth cohorts in the Belgian city of Leuven, it shows empirically that a linearly declining or even concave age-specific fertility pattern, disaggregated by age at marriage, does not imply parity-dependent fertility limitation.
\end{abstract}




\title{
Does an effect of marriage duration on pre-transition fertility signal parity-dependent control?
}

\author{
An empirical test in 19th century Leuven, Belgium \\ dr. Jan Van Bavel
}

Louis Henry coined the concept of natural fertility as the fertility a population would have if it did not use any form of control to limit the number of births (Henry 1953). Later, he specified that birth control exists when the reproductive behaviour of couples depends on whether the number of children already born has reached the maximum number wanted (Henry 1961). Originally, Henry argued that natural fertility was basically a function of woman's age. Whenever a clear influence of age at marriage (or marriage duration) was demonstrated, he interpreted this as a sign of parity-dependent fertility control because marriage duration could be considered as a proxy for the number of children already born. In his later work, however, he abandoned this view, as there was growing evidence of the effect of marriage duration in supposedly natural fertility populations (Henry 1979, pp.19-20).

Indeed, the effect of marriage duration on fertility has been demonstrated for many pre-industrial populations but the meaning of this effect remains unclear (Wrigley et. al. 1997, pp.392-394). Several mechanisms, all associated with marriage duration, may be responsible for it. Often cited are secondary sterility or increased subfecundity in the wake of earlier childbirth, declining coital frequency, the age difference between husband and wife, and, last but not least, parity-dependent fertility control (Knodel 1978; Blake 1985; Trussell and Wilson 1985; Wilson et. al. 1988; Bean et. al. 1990, p.132). 
If, as suggested by Blake (1985), the latter mechanism would be responsible for the marriage duration effect found in many pre-industrial populations, it would contradict the concept of the modern fertility transition as the evolution from parity-independent, natural fertility to parity-dependent, controlled fertility. Whether or not this is the case, however, remains a matter of speculation rather than demonstration.

In spite of the importance of the issue, no research has been published, to our knowledge, that investigates alternative explanations for the marriage duration effect empirically. This is the aim of the present article. It applies multivariate Poisson regression to the fertility data from two Belgian, $19^{\text {th }}$-century birth cohorts in order to investigate empirically whether the marriage duration effect signals parity dependent fertility control or not.

\section{MARRIAGE DURATION AND AGE-SPECIFIC FERTILITY}

It has been common practice in historical demography to use age-specific marital fertility rates to distinguish between natural and controlled fertility. In natural fertility populations, these rates follow a convex function while parity-specific fertility control causes the rates to decline more steeply with woman's age, forming a linear or even concave pattern (Coale and Trussell 1974; Wilson, Oeppen and Pardoe 1988). Indeed, applications of this approach in pre-industrial populations almost invariably found only small departures from the convex, natural fertility pattern (Knodel 1977, 1978; Wilson 1984; Wilson, Oeppen and Pardoe 1988;

Wrigley et. al. 1997). Exceptions are often limited to special populations of social forerunners (Livi-Bacci 1986).

However, many studies failed to control for age at marriage (or marriage duration). Blake (1985) showed for some pre-transition populations that age-specific fertility data that follow the 'natural' pattern in fact exhibit the linear pattern supposedly typical of controlled fertility when age at marriage is taken into account. Specifically, she looked at some $17^{\text {th }}$ and 
$18^{\text {th }}$ century English and French populations, and at a number of mid- $19^{\text {th }}$ century German villages (borrowing data from Wrigley and Schofield 1983, Dupâquier 1979, and Knodel 1978, respectively). The aggregation of different marriage durations in age-specific fertility rates thus artificially gives the impression of the natural, convex fertility pattern, Blake argued, while disaggregation by age at marriage reveals a pattern typical of controlled fertility.

This is not always the case, however. Wrigley et. al. (1997, pp.398-399), for example, found that the clear marriage duration effect in England was limited to the period 1650-1749. In earlier and later periods (1538-1649 and 1750-1837), the effect was much weaker and not fully consistent. Furthermore, and at issue in the present article, the linear age-specific fertility pattern within age-at-marriage groups does not necessarily signal deliberate fertility control (Wilson et. al. 1988). There are several alternative explanations.

One explanation involves involuntary subfecundity or secondary sterility, i.e. sterility brought about as a consequence of giving birth or abortion. Both were associated with considerable risks of infection before modern health practices were adopted. High marriage duration is positively associated with the number of childbirths and, hence, with the risk of infection-induced subfecundity or secondary sterility. This causes the fertility rates to decline more rapidly with age than in the expected convex pattern (Knodel 1978; Trussell and Wilson 1985). Earlier analysis of pre-transition family reconstitution data suggests, however, that the explanatory power of this mechanism may be weak, at least in England. Wrigley et. al. (1997, pp.372-375) found that marriage duration or the number of children born had a very limited impact on women's risk of subsequent sterility.

A second, probably more important alternative explanation for the departure from the convex pattern may be declining coital frequency at higher marriage durations, unrelated to deliberate fertility control, and holding the age of both partners constant. The reasons for this 
negative association have hardly been investigated. Of course, sexual abstinence is a possible strategy for fertility control, but even in the absence of the intention to limit the number of children, coital frequency has been shown to be negatively associated with marriage duration (Wood and Weinstein 1988).

Knodel (1978) has suggested a third mechanism that might help explain the negative effect of marriage duration on fertility, related to the age of the husband. It has been shown that, in European populations before the fertility transition, women who married young tended to marry men who were considerably older, while women who married at older ages tended to marry husbands of similar or younger age. 'Thus, for any given age of wife, husbands of women who married young tended to be older than husbands of women who married at more advanced ages. If fertility of women of a given age declines with the age of the husband, this could help to account for the association between age at marriage and marital fertility' (Knodel 1978, pp.497-498).

Whether or not these mechanisms really explain the effect of marriage duration on agespecific fertility is an important issue for the concept of the fertility transition. If they cannot explain the whole duration-effect and if it can be shown that pre-transition marital fertility was parity-dependent, then the fertility transition can no longer be viewed as a change of fertility regime from natural to controlled. In order to investigate the given alternative explanations, this article introduces empirical indicators for the factors that may be involved.

\section{METHODS}

Historical demographers have detected fertility control indirectly through the difference between observed age-specific fertility and the fertility expected when couples' reproductive behaviour does not depend on the number of children they already have. The more paritydependent fertility control, the higher the difference between observed and expected fertility. 
When the difference is considered to be significant by some standard or rule of thumb, it is concluded that fertility is controlled.

Coale and Trussell (1974), building on the work by Henry, argue that in the absence of fertility control, the general level of marital fertility varies but the age pattern follows a standard schedule. Parity-dependent fertility control causes fertility to diverge from this model. The extent to which observed, age-specific fertility differs from the standard pattern indicates the extent to which couples control their fertility. Let $r(a, i)$ be the marital fertility rate at age $a$ in population $i$. Then the Coale-Trussell model describes it as follows:

$$
r(a, i)=n(a) M(i) e^{m(i) v(a)}
$$

where $n(a)$ is the standard age-pattern of natural fertility, $M(i)$ the general level of fertility in population $i, v(a)$ the standard schedule of age-specific fertility control effects, and $m(i)$ the general level of fertility control in population $i$. Hence, the Coale-Trussell model describes the difference between the actual and standard pattern by a age-specific vector $v(a)$ on the one hand, and a population-specific parameter $m(i)$ for the level of fertility control on the other (Xie 1990).

Whereas the Coale-Trussell model assumes that fertility control is a function of age, the model of marital fertility developed by Page (1977) assumes that it is a function of marriage duration. Like Henry, Coale and Trussell, Page assumes that natural fertility is determined largely by woman's age, but she argues that age is inadequate as a specification for the pattern of fertility control. 'Control of fertility is usually taken to depend primarily on previous fertility experience: age cannot bear the same relation to fertility experience in all populations, because the age at which women begin childbearing can vary widely' (Page 1977, p.86). Therefore, duration of marriage is a more direct specification than age for detecting patterns of fertility control. However, age cannot be discarded from a general model of marital fertility because it remains an important physiological determinant of fertility. Therefore, Page (1977) 
proposes a model incorporating both age and marriage duration. Let $r(a, d, i)$ be the fertility of population $i$ at age $a$ and marriage duration $d$. The Page model implies the following identity:

$$
r(a, d, i)=n(a) M(i) e^{d \beta(i)}
$$

In this model, $\beta(i)$ represents the level of fertility control: it quantifies to what extent actual fertility diverges from the natural pattern when marriage duration $d$ increases. The latter parameter is considered to be a better proxy for parity than age.

In this article, parity is introduced explicitly into the model, together with age and marriage duration, in order to decide on empirical grounds whether the marriage duration effect is due to parity-dependent fertility control. If, on the one hand, marriage duration does have an effect on age-specific fertility and parity does not, then neither secondary sterility nor parity-dependent fertility control can explain the marriage duration effect. Suppose, on the other hand, that we do find that parity significantly affects age-specific fertility. Then both secondary sterility and parity-dependent fertility control might be present. The challenge is to distinguish between the two latter mechanisms.

In order to do so, fertility should be viewed from the perspective of reproduction, distinguishing net parity from crude parity: the former is the number of children still alive at some point in time, while the latter includes all children already born, alive as well as deceased. Hence: net parity equals crude parity minus the number of deceased children. If net parity has a statistically significant effect on age-specific fertility, even after controlling for crude parity (or, equivalently, the number of deceased children), this would strongly suggest that fertility was being controlled with a desired offspring in mind. If, however, only marriage duration and crude parity affect marital fertility significantly and net parity does not, then declining coital frequency and secondary sterility are sufficient to explain the departure from the standard convex scheme. The marriage duration effect would, then, demonstratedly not imply fertility control. 
The inclusion of crude parity is essential for the analysis in order to control for two opposing mechanisms behind the bivariate association between the number of children already born and subsequent fertility. On the one hand, we expect a positive association between crude parity and fertility because parity, at a given age and marriage duration, is positively associated with fecundability. The higher the fecundability, the shorter the interbirth intervals, and the higher the crude parity attained. On the other hand, every birth entails some risk of secondary sterility or subfertility, implying zero or lower subsequent fertility. Of course, the relation between crude parity and secondary sterility is more complex, because selection effects are at work as well: women who become secondarily sterile at some lower parity, will never reach a higher parity. At issue here, however, is the meaning of the effect of marriage duration on fertility. The literature suggests that it may be due, to some extent, to childbearing induced sterility. Therefore, if marriage duration still affects fertility significantly after controlling for parity, then that duration effect cannot be explained away by secondary sterility.

Net parity equals crude parity minus the number of deceased children. Therefore, the effect of net parity on the fertility rate, after controlling for crude parity, is exactly the opposite of the effect of the number of children lost. To some extent, then, we are measuring the effect of infant mortality on fertility, which is known to be positive, even in the absence of fertility control (Preston 1978). This would blur or even invalidate the analysis because net parity is included in order to detect parity-dependent fertility control while in fact it is capturing an infant mortality effect as well. Therefore, we should control for that effect as well. The following analysis does this by including a dummy variable that represents the survival or dead of the previous child. Finally, the age difference between the spouses is introduced into the analysis to assess the importance of that factor. 
Because of the introduction of crude parity, net parity, infant survival, and the age difference between the spouses into the age- and duration-specific analysis, it is no longer feasible to model fertility on an aggregated level. Rodriguez and Cleland (1988) showed how the Coale-Trussell and the Page model can be reformulated on the individual level, allowing more factors to be introduced in a multivariate analysis. Following their Poisson-approach, and extending the Page model, marital fertility can be written as a function of a vector $X$ of $k$ characteristics of marriage $i$ observed at woman's age $a$ :

$$
\begin{aligned}
& r(a, i)=\left(\frac{B(a, i)}{P(a, i)}\right)=\mu \cdot n(a) \cdot e^{\beta_{k} X_{k}(a, i)} \\
& \Rightarrow \log B(a, i)=\log P(a, i)+\log \mu+\log n(a)+X_{k}(a, i) \beta_{k}
\end{aligned}
$$

where $B(a, i)$ is the number of births in marriage $i$ at the wife's completed age $a$, and $P(a, i)$ the corresponding exposure time (or time at risk). The unknown parameters in the model are $\mu$, the general level of fertility in the population, and the vector $\beta$ containing the $k$ effectparameters of the individual covariates. In the following regression analysis, these covariates are marriage duration, crude parity, net parity, a dummy representing death or survival of the previous child, and the age difference between the spouses. Clearly, some of these are highly correlated, but this does not jeopardize the validity of the analysis as long as we have no perfect multicollinearity (Berry 1993).

\section{DATA}

The model described in equation (3) will be applied as a Poisson-regression to the fertility data collected for two $19^{\text {th }}$-century generations living in the Belgian provincial town of Leuven. This is a Dutch-speaking traditional trades and crafts centre with a French-speaking bourgeois elite. The first generation consists of all married couples with at least one of the spouses born in 1830 who had ever lived in Leuven between 1847 and 1880. The second 
generation includes all couples with man or wife born in 1864 and who had ever lived in the same town between 1881 and 1910. These two generations (called G1830 and G1864) were chosen in such a way that the first completed its fertile life course before any signs of marital fertility decline were visible on the aggregated level. The marital fertility transition started in Leuven in the early 1880 's, when the second generation was reaching adulthood. The data were collected for the period 1846-1910 from the population registers and from civil registration (birth, death, and marriage certificates). Gutmann and van de Walle (1978) and Leboute and Obotela (1988) describe the general characteristics of these sources. Van Bavel (2002) describes the Leuven sample in detail, while table 1 gives sample-size information in terms of the observed number of person years by age and generation.

[Insert here Table 1]

Table 1 also gives the marital fertility rates and maximum likelihood estimates of the parameters $M$ and $m$ in the Coale-Trussell model, fitted to the data following the Poisson regression approach (Broström 1985). Analysis of the age-specific fertility rates suggests that, by conventional interpretation (Coale and Trussell 1974, 1978), the first generation did not control fertility in a parity-dependent way $(m=0.077)$, while the second generation started to exhibit a pattern typical of parity-dependent fertility control $(m=0.472)$. It has been shown, however, that the Coale-Trussell model is incapable of detecting small but significant proportions of the population who are controlling their fertility (Okun 1994). Hence, a minority of the oldest generation may already have been limiting births.

In addition, breaking down these age-specific rates by age at marriage yields a pattern that suggests the existence of fertility control in the oldest generation as well: already in G1830, marital fertility rates decrease linearly with woman's age, controlling for her age at 
marriage. This can be seen in figure 1, and analysis using the Page model confirms the visual impression: maximum likelihood estimation of the $\beta(i)$-parameter in equation (2) yields values that differ significantly from zero in the oldest as well as in the youngest generation, suggesting deviance from the natural fertility pattern in both cases (Page 1977; Van Bavel 2002, pp.98-104). The aim of the following multivariate regression analysis is to see whether this pattern really indicates parity-dependent fertility control.

\section{[Insert here Figure 1]}

The dependent variable $r(a, i)$ is the number of births to marriage $i$ at completed age $a$, divided by the number of person-years marriage $i$ was observed in Leuven. Age is measured here in

one-year age intervals, not in five-year categories, starting from the wife's $20^{\text {th }}$ birthday. As a consequence, the numerator of the dependent variable hardly ever exceeds one, because giving birth more than once a year is exceptional. The denominator equals one when a marriage was observed during a full year. In case of censoring, the denominator is a fraction of one. Marital duration is expressed in the number of completed years, measured at the exact age $a$ of the wife. The age difference between man and wife is expressed in exact number of years. Net parity is only known for couples that had always been under observation in the Leuven population registers since the start of the marriage. Hence, left-censored cases had to be excluded from the regression. After this exclusion, 3071.6 person-years were still available for analysis from the first generation, and 4448.9 person-years from the second.

\section{FINDINGS}

As explained by Rodriguez and Cleland (1988), equation (3) describes a type of model that falls in the class of generalized linear models. An important implication is that maximum 
likelihood estimation of the unknown effect-parameters is possible, yielding estimates of the standard errors and the likelihood ratio stastistic as well (Long 1997). The results of this fitting procedure, applied to the Leuven cohort data, are in Table 2.

Judged by any conventional standard, the model fits the observed fertility data quite well for both generations. The bottom of Table 2 gives goodness-of-fit statistics, namely deviance and the Bayesian Information Criterion (BIC). The latter measure is widely used because it takes into account both the deviance, i.e. the difference between observed and predicted data, the parsimony of the model, and the sample size. Negative BIC-values indicate that the model is statistically acceptable (Long 1997, pp.109-112), which is clearly the case here.

[Insert here Figure 2]

Figure 2 gives a visual impression of the fit. It graphs observed and predicted fertility rates by woman's age and by marriage duration. Observed rates are somewhat erratic because of sampling error, but the model predicts the pattern quite well. There is one systematic difference between observed and model rates: as has already been noted by Rodriguez and Cleland (1988), the model tends to overestimate fertility in the year immediately following first marriage and to underestimate it a year later. It is most probably a consequence of the special nature of the first year of marriage, in which fertility tends to be high but represents substantially less than a full year of exposure time. Anyway, the difference between observed and predicted fertility rates during the first two years of marriage tends towards selfcompensation (as in Rodriguez and Cleland 1988) and is not important for present purposes. 
The first and most important substantial conclusion that can be drawn from the regression, is that the negative effect of marriage duration on fertility can clearly not be explained away by the effects of secondary sterility and parity-dependent fertility limitation. Indeed, even after controlling for crude and net parity, marriage duration has a strong and statistically significant effect on marital fertility. Table 2 gives the regression parameters in an exponentiated form in order to make them substantially interpretable as a factor effect parameter. Hence, the estimated effect of marriage duration in G1830 implies that, on average and holding other factors in the model constant, fertility decreased with a factor 0.953 or about $-5 \%$ each additional year a marriage has lasted. In G1864, fertility went down with marriage duration about twice as fast ( 0.899 or $-10 \%$ each additional marriage year).

[Insert here Table 2]

The effect of the age difference between the spouses, if any, was statistically significant in none of the two generations after controlling for the other covariates. Other specifications of the age difference have been tested, including categorical and non-linear ones, but this never yielded a significant effect. The regression parameter for age difference becomes significant only after deletion of crude and net parity from the model. Indeed, age difference is highly associated with the parity that has been reached: women who marry relatively early, tend to do this with older men. This group also reaches the highest parities. Women who marry relatively late, tend to marry younger men but do not reach high parities anymore. Hence, the suggested effect of age difference on fertility may be spurious.

Crude parity had a positive effect on age-specific marital fertility in both generations: given age and marriage duration, the marriages that are subsequently more fertile are the ones that have been more fertile in the past. In other words: holding everything else constant, 
women who already had given birth to more children, had on average more children in the future, presumably because of higher fecundability or restricted breastfeeding. To be sure, these are the women who had run the highest risks of becoming secondary sterile as well. Hence, given the effect of marriage duration after controlling for parity, in both generations duration had an effect that can not be reduced to the effect of secondary sterility.

Clearly, it can also not be reduced to the effect of parity-dependent fertility control. As explained above, the model includes net parity in order to detect fertility control in both generations. According to the estimators given in Table 2, fertility did not depend significantly on the number of children alive in the first generation. In the second generation, it did, even after controlling for survival of the previous infant. The effect of the dead of the previously born infant was the same in both generations: it increased fertility with about $55 \%$. As explained above, controlling for this natural fertility determinant is essential in order to allow the effect of net parity to be interpreted as fertility control. Indeed, if the infant survival dummy is deleted from the regression (as has been done in Van Bavel 2002, not in Table 2), the coefficient for net parity becomes statistically significant already in G1830, spuriously suggesting parity-dependent fertility control. In fact, there was no parity-dependent fertility control in the first generation. Hence, the negative relationship between marriage duration and age-specific fertility did not signal fertility control, at least not in the pre-transition population of Leuven.

\section{CONCLUSION}

Bean et. al. (1990) state that no single explanation can be provided for the relationship between age at marriage and fertility. Like Wilson et. al. (1988), among others, they posit three plausible explanations. 'These include the possibility of reduced coital frequency associated with duration of marriage and increased subfecundity associated with parity, as 
well as the adoption of some limited form of parity-dependent family limitation. If the latter condition is present, then the applicability of the concept of 'natural fertility' to the population must be questioned' (Bean et. al. 1990, p.132). In addition, Knodel (1978) includes the age difference between spouses in his list of plausible explanations. The importance of these alternative mechanisms has never been weighed empirically in a pre-transitional population. Application in this article of a Poisson regression approach to marital fertility data from a pretransition birth cohort suggests that even a strong marriage duration effect by no means has to imply parity-dependent stopping behaviour. Marriage duration has a negative effect on fertility which cannot be reduced to the combined effect of parity-dependent control, secondary sterility (or subfecundity), and the age difference between spouses. The most important causal mechanism at work seems to be what Charles F. Westoff has described as 'the saddest curve in the world': the decline of coital frequency associated with increasing marriage duration. If these results can be replicated for other pre-transition populations, then the claim made by Blake (1985), that 'the rates disaggregated by age at marriage suggest possible fertility control after a given number of births', can finally be overruled on empirical grounds. 


\section{References}

Bean, L. L., G. P. Mineau, and D. L. Anderton. 1990. Fertility Change on the American Frontier: Adaptation and Innovation. Berkeley: University of California Press.

Berry, W. D. 1993. Understanding Regression Assumptions. Newbury Park/London: Sage.

Blake, J. 1985. “The fertility transition: continuity or discontinuity with the past?", International Population Conference 4. Liège, IUSSP, pp. 393-405.

Broström, G. 1985. "Practical aspects on the estimation of the parameters in Coale's model for marital fertility", Demography 22(4): 625-631.

Coale, A. J. and T. J. Trussell. 1974. "Model fertility schedules: variations in the age structure of childbearing in human populations", Population Index 40(2): 185-258.

Coale, A. J. and T. J. Trussell. 1978. "Technical note: finding the two parameters that specify a model schedule of marital fertility", Population Index 44: 203-213.

Dupâquier, J. 1979. "Etude Comparative Des Données Sur La Fécondité Dans 25 Monographies Concernant Le Bassin Parisien à La Fin Du XVIIe Siècle Et Au Début Du XVIIIe." Pp. 409-39 in Natural Fertility / Fécondité Naturelle, eds. H. Leridon and J. Menken. Liège: IUSSP.

Gutmann, M. P. and E. van de Walle. 1978. "New Sources for Social and Demographic History: The Belgian Population Registers", Social Science History 2(2): 121-143.

Henry, L. 1953. "Fondements théoriques des mesures de la fécondité naturelle”, Revue de l'Institut International de Statistique 21(3): 135-151.

Henry, L. 1961. "Some Data on Natural Fertility", Eugenics Quarterly 18:81-91.

Henry, L. 1979. "Concepts actuels et résultats empiriques sur la fécondité naturelle", in H. Leridon and J. Menken (eds.), Natural Fertility / Fécondité naturelle. Liège: IUSSP, pp.15-28.

Knodel, J. 1978. “Natural fertility in pre-industrial Germany”, Population Studies 32(3): 481-510.

Leboutte, R. and R. Obotela. 1988. "Les registres de population en Belgique. Genèse d'une technique administrative et d'une source de démographie historique", Handelingen van de Koninklijke Commissie voor Geschiedenis (3-4): 285-305.

Livi-Bacci, M. 1986. "Social-Group Forerunners of Fertility Control in Europe." Pp. 182-200 in The Decline of Fertility in Europe, eds. A. J. Coale and S. C. Watkins. Princeton (N.J.): Princeton University Press.

Long, J. S. 1997. Regression Models for Categorical and Limited Dependent Variables. London: Sage.

Okun, B. S. 1994. "Evaluating Methods for Detecting Fertility Control: Coale and Trussell's Model and Cohort Partity Analysis." Population Studies 48(2):193-222.

Page, H. J. 1977. "Patterns underlying fertility schedules: a decomposition by both age and marriage duration", Population Studies 31(1): 85-106.

Preston, S. H. 1978. The Effects of Infant and Child Mortality on Fertility. New York: Academic Press.

Rodriguez, G. and J. Cleland. 1988. "Modelling marital fertility by age and duration: an empirical Appraisal of the Page model", Population Studies 42(2): 241-257.

Jan Van Bavel 
Trussell, J. and C. Wilson. 1985. "Sterility in a population with natural fertility", Population Studies 39(2): 269286.

Van Bavel, J. 2002. Van natuurlijke naar gecontroleerde vruchtbaarheid? Geboortebeperking in Leuven, 18461910. Leuven: Leuven University Press.

Wilson, C., J. Oeppen, and M. Pardoe. 1988. "What is natural fertility? The modelling of a concept", Population Index 54(1): 4-20.

Wood, J. W. and M. Weinstein. 1988. “A model of age-specific fecundability”, Population Studies 42(1): 85113.

Wrigley, E. A. and R.S. Schofield. 1983. "English Population History From Family Reconstitution: Summary Results 1600-1799." Population Studies 37(2):157-84.

Wrigley, E. A., R. S. Davies, J. E. Oeppen, and R. S. Schofield. 1997. English Population History From Family Reconstitution 1580-1837. Cambridge: Cambridge University Press.

Xie, Y. 1990. "What is natural fertility? The remodeling of a concept", Population Index 56(4): 656-663. 
Table 1. Number of person-years observed, age-specific marital fertility rates, and maximum likelihood estimates of the Coale-Trussell parameters, Leuven (Belgium) by generation

\begin{tabular}{|c|c|c|c|c|}
\hline & G1830 & & G1864 & \\
\hline Woman's age & $\mathrm{P}(\mathrm{a}) *$ & fertility rate $n(a)$ & $\mathrm{P}(\mathrm{a}) *$ & fertility rate $n(a)$ \\
\hline $20-24$ & 386.96 & 0.408 & 688.65 & 0.402 \\
\hline $25-29$ & 866.80 & 0.392 & 1433.21 & 0.320 \\
\hline $30-34$ & 1150.96 & 0.334 & 1702.23 & 0.254 \\
\hline $35-39$ & 1193.25 & 0.272 & 1582.63 & 0.154 \\
\hline $40-44$ & 1024.20 & 0.144 & 1270.87 & 0.080 \\
\hline $45-49$ & 889.65 & 0.021 & 441.75 & 0.023 \\
\hline Coale-Trussell model: & $\mathrm{M}=0.904$ & $\mathrm{~m}=0.077$ & $\mathrm{M}=0.851$ & $\mathrm{~m}=0.472$ \\
\hline
\end{tabular}

* $P(a)=$ exposure, or the number of person-years observed in the age-interval

Source: the Leuven cohort fertility project (Van Bavel 2002) 
Table 2: Poisson regression of the age-specific marital fertility of two generations: effects of marriage duration, the age difference between the spouses, crude and net parity, and death of the lastborn infant (Leuven, Belgium, 1846-1910)

Table 2

\begin{tabular}{l|ccc|ccc}
\hline & \multicolumn{3}{|c|}{ Generation 1830 } & \multicolumn{3}{c}{ Generation 1864 } \\
& $\mathrm{e}^{\text {coëff. }}$ & s.e. & $\mathrm{p}$ & $\mathrm{e}^{\text {coëff. }}$ & s.e. & $\mathrm{p}$ \\
\hline Overall marital fertility level & $\mathbf{0 . 8 5 7}$ & 0.074 & 0.0355 & $\mathbf{0 . 6 8 0}$ & 0.065 & $<.0001$ \\
Marriage duration & $\mathbf{0 . 9 5 3}$ & 0.012 & $<.0001$ & $\mathbf{0 . 8 9 9}$ & 0.010 & $<.0001$ \\
Age difference (husband-wife) & 0.996 & 0.006 & 0.4545 & 0.997 & 0.007 & 0.7151 \\
Crude parity & $\mathbf{1 . 1 2 2}$ & 0.039 & 0.0031 & $\mathbf{1 . 3 0 0}$ & 0.037 & $<.0001$ \\
Net parity & 0.970 & 0.045 & 0.4919 & $\mathbf{0 . 9 0 6}$ & 0.045 & 0.0281 \\
Previous infant died (1=Yes, 0=No) & $\mathbf{1 . 5 5 5}$ & 0.104 & $<.0001$ & $\mathbf{1 . 5 6 9}$ & 0.099 & $<.0001$ \\
\hline & & $\mathrm{df}$ & $\mathrm{N} *$ & & $\mathrm{df}$ & $\mathrm{N} *$ \\
Deviance & 1885.2 & 3164 & 3170 & 2557.4 & 4611 & 4617 \\
BIC & -23621 & & & -36348 & & \\
\hline
\end{tabular}

* $\mathrm{N}=$ number of age intervals in the sample

Source: the Leuven cohort fertility project (Van Bavel 2002) 


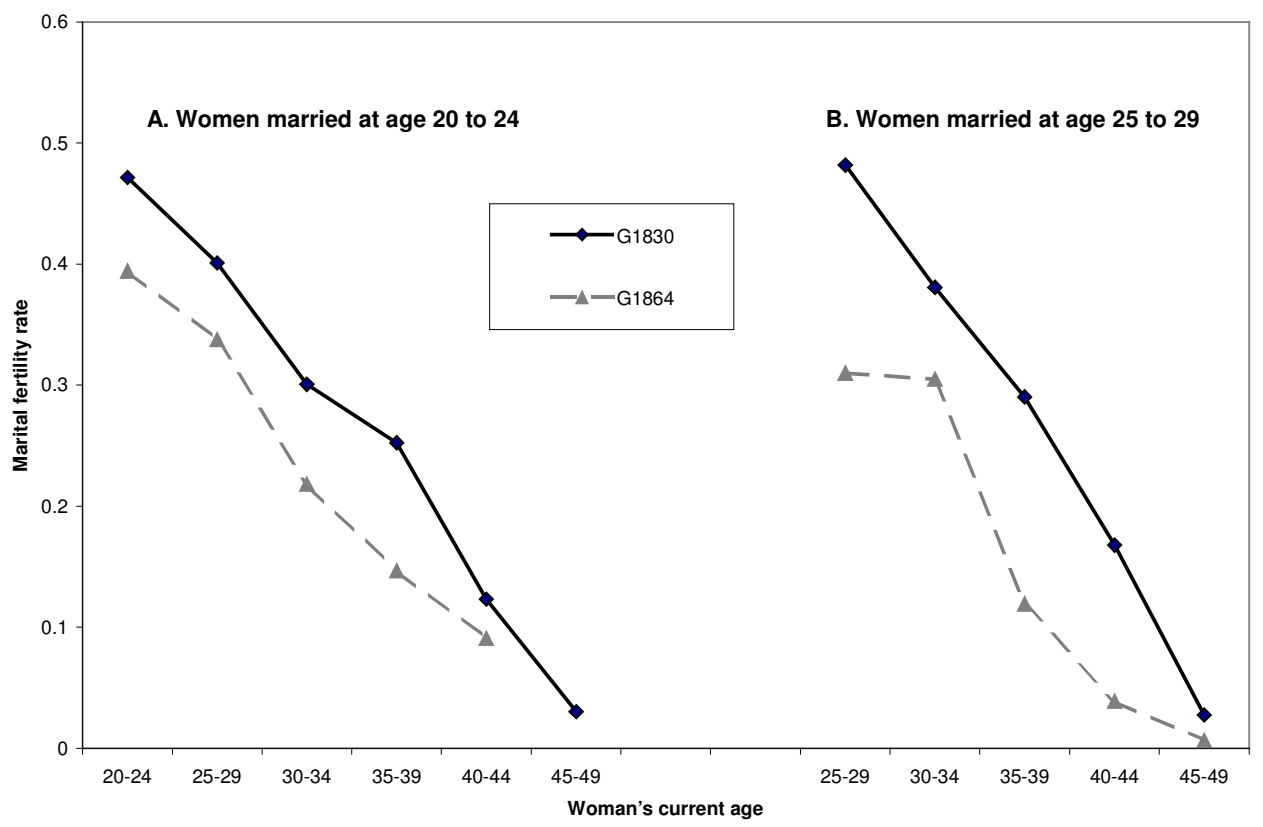

Figure 1. Age-specific marital fertility by generation and woman's age at marriage, Leuven (Belgium), 1846-1910

Source: the Leuven cohort fertility project (Van Bavel 2002) 

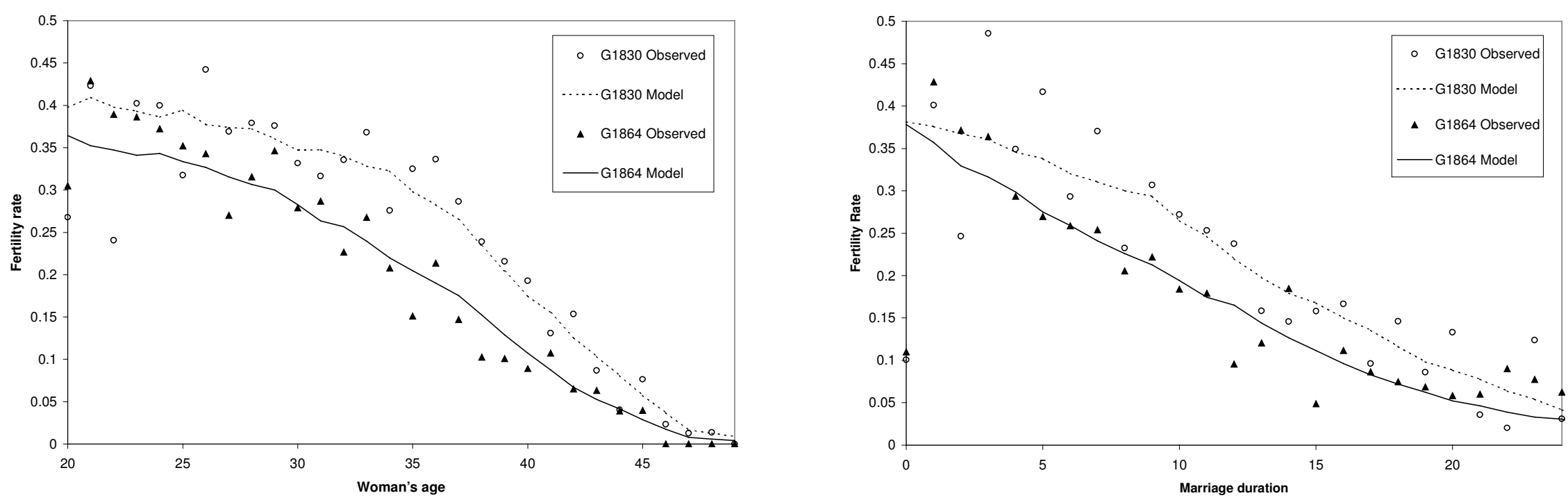

Figure 2. Observed and fitted age-specific and duration-specific marital fertility rates

Source: the Leuven cohort fertility project (Van Bavel 2002) 